as great as that deduced from Planck's formula for this case. In connection with similar work of his own, Mr. Jeans (Phil. Mag., July) has just pointed out that I have introduced a redundant factor 8 by counting negative as well as positive values of my integers $\xi, \eta, \zeta$.

I hasten to admit the justice of this correction. But while the precise agreement of results in the case of very long waves is satisfactory so far as it goes, it does not satisfy the wish expressed in my former letter for a comparison of processes. In the application to waves that are not long, there must be some limitation on the principle of equi-partition. Is there any affinity in this respect between the ideas of Prof. Planck and those of Mr. Jeans?

Terling Place, Witham, July 7 .

Rayleigh.

\section{Proposed Observation of Mercury during the Solar Eclipse.}

DURING the eclipse of the sun on August 30 next there will be an opportunity of making a very interesting observation on the planet Mercury, to which I ask permission to direct attention.

Mercury at the time of the eclipse will be very close to the line joining the earth and sun-about $2^{\circ} 54^{\prime}$ south and $2^{\circ} 54^{\prime}$ preceding the sun-i.e. at an angular distance from the sun's centre of nearly $4^{\circ} 6^{\prime}$. Accordingly, the illuminated part of Mercury will be an excessively thin crescent which, if Mercury have an atmosphere, will have its horns prolonged by atmospheric refraction.

If a sufficiently skilled observer is provided with a telescope upon which he can use a power of 200 without loss of definition, and mounted-probably as an altazimuth-so that it can be set beforehand upon Mercury, the apparent size of Mercury will be that which would be presented by a circle one-tenth of an inch across, viewed with the naked eye from a distance of ten inches.

This ought to be sufficient magnification to see whether the horns of the crescent are prolonged, and, if so, it, is perhaps not impossible that the light would be sufficient to enable a spectrum of the tips of the crescent to be seen.

If the whole of this programme can be carried our, we should find out whether Mercury has an atmosphere, and possibly learn something as to the constituents of the atmosphere.

30 Ledbury Road, W., July ro. G. Johnstone Stoney.

\section{The Planet Uranus.}

Astronomical amateurs will have an excellent opportunity of identifying Uranus on about July 16 next, for the planet will be in conjunction with the star I Sagittarii (mag. 5.3) on the night following that date.

The position of Uranus at transit (Ioh. 30m.) will be :R.A. $18 \mathrm{~h} .5 \mathrm{~m} .58 \mathrm{~s}$., Dec. S. $23^{\circ} 4^{\prime}{ }^{\prime} \mathrm{I}^{\prime \prime}$,

while that of the star will be (1905.5) :-

R.A. $18 \mathrm{~h} .5^{\mathrm{m}}$. $57^{\text {s., }}$ Dec. S. $23^{\circ} 43^{\prime}$ I $6^{\prime \prime}$,

so that the planet will pass about $\mathrm{I}$ minute of arc north of the star. The latter may be easily picked up, as it is nearly $4^{\circ} \mathrm{S}$. of the triple star $\mu$ or 13 Sagittarii (mag. $4 \cdot \mathrm{I}$ ).

Unfortunately, the objects will be low in altitude $\left(15^{\circ}\right)$, and the moon happens to be full on the date of conjunction.

On June 24 and July 8 I found Uranus a little fainter than the star I Sagittarii. I have carefully observed the planet on several nights in a $12 \frac{1}{2}$ in. Calver reflector, powers 100 to 475 . The disc appeared faint with a bluish tinge, and no belts or other markings could be detected, but the telescope is too small to deal effectively with an object of this description

Bristol, July 9.

W. F. Denning.

\section{The Exploration of the Atmosphere above the} Atlantic.

A PLAN for systematic work of this kind, which was proposed by the writer in I9OI at the Glasgow meeting of the British Association (Report, p. 724) after he had obtained the first observations with kites flown from a Transatlantic steamer, is now being partially realised. Last summer Prof. Hergesell, on board the Prince of Monaco's steamyacht Princess Alice, executed sixteen kite-flights above that part of the Atlantic bounded by Spain, the Canaries and the Azores, but without finding the expected southwest anti-trade, although a height of nearly i5, ooo feet was reached (Nature, vol. Ixxi. p. 467). The present expedition, which will repeat Prof. Hergesell's investigations and continue them further south; is made possible through the cooperation of our distinguished French colleague, M. Teisserenc de Bort, whose steam-yacht Otaria, of $35^{\circ}$ tons, with a speed of II knots, and fully equipped for aërial exploration, has just sailed from Gibraltar, and, at the joint expense of her owner and the writer, will proceed towards the equator by way of Madeira, Canary and Cape Verde Islands, making frequent soundings with kites through the trade winds and equatorial calms. By means of the self-recording instruments lifted by the kites, it is expected that there will be ascertained the thermal and hygrometric conditions of the various strata traversed, and the depth and force of the trade wind in the different latitudes. If the kites do not reach the south-west return trade, which has been observed on the Peak of Teneriffe, the vertical range of observation may be increased by liberating hydrogen balloons from Madeira and noting their drift.

Mr. Clayton, meteorologist of the Blue Hill Observatory, left Boston on June 3 to join the Otaria at Gibraltar. During his voyage to the Azores on the White Star liner Romanic he flew kites, with instruments attached, almost daily to the height of from five-eighths to three-quarters of a mile, thus securing the highest observations in midAtlantic, and it is interesting that this was done on June 7 , the day appointed for the international observations in the upper air here at Blue Hill and in Europe. In general, the temperature was found to decrease with altitude at less than the adiabatic rate, and the relative humidity to decrease also, but in one ascent there was a rise of temperature with altitude, preceding a change of wind from west to south. A new form of folding kite was employed, and it is encouraging to learn that the heights attained were limited by the length and strength of the wire on the hand-reel, which did not permit more than one of these kites to be attached. On the two days when no flights were made, a following wind became too light on board the steamer to lift the kites, whereas, on the yacht, this condition would have been obviated by simply lying-to, or steaming against the wind.

While the cruise of the Otaria, which is to last only six weeks, can hardly do more than elucidate certain questions relating to the high atmosphere in the tropics, it will demonstrate the possibilities and difficulties attending the extensive survey that the writer desires to undertake, and which received the endorsement of the International Meteorological Committee at Southport in 1903 . A. LaWREnce Rotch.

Blue Hill Meteorological Observatory, Hyde Park, Mass., U.S.A., June 26.

\section{Ancient Antarctica.}

Prof. H. F. OsBorn has said that the demonstration of "the former existence of an Antarctic continent is one of the greatest triumphs of modern science." But even if this be true, everyone must allow that it occurred a very long time ago. This is proved by the great differences that exist between the floras and faunas of the three great southern continents. These differences are much greater than those between the floras and faunas of North America and Eurasia and consequently the land connections must have been broken up in the south long before they were in the north. We infer the former existence of an Antarctic continent from the existence of granite and foliated schists in South Victoria Land, and evidence that it was formerly connected with northern lands is found in the existence of flightless insects living there in the few patches of mosses and lichens which manage to struggle through the winter. These insects are not flightless through degeneration, but belong to an order which never possessed wings.

NO. I 863 , VOL. 72 ] 